Anz. Schädlingskde., Pflanzenschutz, Umweltschutz 50, 14 (1977)

(c) 1977, Verlag Paul Parey, Berlin und Hamburg

ISSN 0003-6307/ASTM-Coden: ASPUCR

\title{
Rundschau
}

\section{Pater Romidius Girtler zum Gedenken}

Am 8. Januar 1976 beging der führende Südtiroler Bienenforscher, Imker und "Wanderlehrer" der Bienenkunde Pater Romidius GIRTLer seinen 90. Geburtstag, doch bereits am 10. Mai 1976 verschied er im Deurschordenskloster in Siebeneich bei Bozen.

Romidius Girtiers Lebensinhalt war die eingehende Erforschung der Biologie der Honigbiene und die Bienenzucht. Darüber hinaus befaßte er sich mit vielerlei Naturgeschehen. Frühzeitig war die Liebe und Begeisterung zur Imkerei in ihm erwacht. In einem Briefe schrieb er mir: "Schon als Schulbub habe ich mich mit den Bienen befreundet und in Flains bei Sterzing bei einem Bauer, der gegen 12 Völker in Strohkörben hatte, mit Freuden mitgearbeitet. Im Jahre 1912 habe ich in Lana im Deutschordenskonvent die Bienenzucht übernommen. Es waren 30 Völker in Albertiblätterstöcken." Diese hat er dann umgebaut und auf 50 Völker erhöht. „Damals gab es noch keine Spritzerei und Honig in Menge. Der Honigertrag war durchschnittlich $30 \mathrm{~kg}$ pro Volk. “

Während des ersten Weltkrieges gab er bereits Anleitungen zur Bienenzucht und wurde schließlich "Wanderlehrer". Er hielt zahlreiche Vorträge zur Imkerei und Apidologie, nicht nur in Südtirol, Bayern, Osterreich, sondern in fast allen deutschen Ländern. Seinen letzten Vortrag hielt er am 25. September 1971 beim zweiten "Südtiroler Entomologentag" auf Sonnegg in Dietenheim bei Bruneck. Der Vortrag war erfüllt mit gesicherten Tatsachen und kennzeichnenden Lebenserinnerungen, ein Vortrag, den man nicht vergißt.

Die ersten Veröffentlidhungen über Bienenkunde und Bienenzucht aus seiner Feder erschienen während des ersten Weltkrieges unter dem Namen „Much“. Außer zahlreichen Veröffentlichungen in Fachzeitschriften stammt das in 6 Auflagen erschienene Buch über die Biene und die Bienenzucht "Der Bienenmuch" von ihm, was den Anstoß gab, daß er im In- und Auslande nicht unter dem Namen RomidIUS GIRTLER sondern als der „Bienen-Much“ bekannt und geschätzt wurde. Er führte die Bienenzucht auf neuzeitliche Höhe, auch der "Muchstock“, eine Blätterbeute in zwei Etagen, wurde von ihm entwickelt.

Der Bienen-Much hatte ein umfassendes Wissen. So war ihm z. B. schon früh bewußt, daß das Vorhandensein von Pollen enthaltenden Blütenhonig für die Gesunderhaltung der Bienen über den Winter unerläßlich ist.

Ein feiner Humor zeichnete ihn aus. Es sei nur eines seiner Erlebnisse bei einem Vortrage, den er mir in einem Briefe schilderte, wiedergegeben: „Es war in der Faschistenzeit in Italien, wo jede Versammlung angemeldet werden mußte. Zum Vortrag kam der Mareschallo mit zwei Karabinieri. Nach meinem Vortrag ging der Mareschallo auf mich $\mathrm{zu}$ und sagte, $\mathrm{Ha}$ parlato della politica!'. Id erwiderte: ,No signor Mareschallo'. Er: ,Ha parlato della regina'. Ich: , Si signor Mareschallo, ma della regina degli api.'! $\mathrm{Da}$ reichte er mir lächelnd die Hand, sagte „Bene‘ und verließ die Versammlung."

Sein unermüdliches, selbstloses und segensreiches Wirken um die Imkerei und um die Bienenkunde fußte auf tiefgründigem Wissen, reicher Erfahrung, gepaart mit Herzensgüte.

Es ist nur natürlich, daß dem verdienten Bienen-Much, Pater Romidius GrRTLER, Ehrungen und Auszeichnungen zuteil wurden. 1949 wurde ihm vom Osterreichischen Imkerbund die Goldene Weippl-Medaille und 1966 vom Bayerischen Landesverband die Goldene Zander-Medaille verliehen. In der Geschichte der Imkerei und der Bienenkunde hat er seinen festen Platz.

Alle die Romidius GIRTLER, den Bienen-Much kannten, werden dieser großen Persönlichkeit umfassenden Wissens, großer Güte, hoher Menschlichkeit und Herzenswärme so- wie echten, unbeugsamen Mannestums ein stetes respektvolles und ehrendes Gedenken bewahren.

Erwin Schimitschek

\section{Leibniz-Medaille für Max Hoffmann, Halle}

Gelegentlich der diesjährigen traditionellen Festsitzung der Akademie der Wissenschaften der DDR anläßlich des 330. Geburtstages von GotTtrRIED WILHELM LEIBNIZ wurde dem bekannten, heute in Halle/Saale im Ruhestand lebenden Nagetierforscher Max Hoffmann vom Präsidenten der Akademie, Prof. Dr. Dr. h. c. Hermann Klare die Leibniz-Medaille verliehen. Prof. KLARE betonte in seiner Laudatio, daß sich Max Hofrmann in jahrzehntelanger Tätigkeit insbesondere um die Erforschung der Lebensweise der Bisamratte und ihrer wirtschaftlichen Bedeutung hohe Verdienste erworben habe. Besonders hoch einzuschätzen sei die Tatsache, daß Max HoffMANn sich als Autodidakt seine großen Kenntnisse angeeignet habe. Die Medaille ist die höchste von der Akademie zu vergebende Auszeichnung und ist in Erinnerung an GOTTFRIED Wilhelm LerbNiz gestiftet worden, der als vielseitiger und bahnbrechender Gelehrter auf fast allen Wissensgebieten um 1700 der Initiator zur Gründung der Berliner Akademie der Wissenschaften und ihr erster Präsident war.

Über den Lebensweg und das Schaffen von Max HoFrManN wurde von Prof. Dr. Hans Petzsch $(\dagger)$ in dieser Zeitschrift wiederholt berichtet $(37,172 ; 42,140-141$; 47, 144). Max HoffmanN war in erster Linie ein Mann der Praxis, ergänzte dieses aber durch Zusammenarbeit mit wissenschaftlichen Instituten, Studium der Weltliteratur, durch Teilnahme an internationalen Tagungen (u. a.der EPPO) und durch Auslandsreisen. Ab 1942 begann er mit kleineren Veröffentlichungen, die schließlich zu seiner bekannten Bisamratten-Monographie (1959) mit einer darin enthaltenen Bibliographie führte. Inzwischen veröffentlichte er 3 Nachträge mit rund $5000 \mathrm{Zitaten;}$ ein 4. und 5. Nachtrag mit weiteren 1800 Zitaten sind im Druck. Seine Publikationen über den Elbe-Biber (1967), über Nutria (1952), Mink (1974) und Wanderratten $(1974,1976)$ trugen der Nagetierforschung wertvolle Erkenntnisse zu. MAX HofFMANN hat mancherlei Auszeichnungen und Ehrungen erhalten, die Leibniz-Medaille dürfte ihr Höhepunkt sein. Hierzu sei ihm von der Herausgebergemeinschaft des Anzeiger für Schädlingskunde, Pflanzenschutz, Umweltschutz herzliche Gratulation ausgesprochen, welcher sich alle anschließen, die Max Hoffmann kennen und aus seinen Publikationen Nutzen und Anregungen erhalten haben.

Herbizide wirken nicht auf Wurzelbrand bei Zuckerrüben

Herbizide haben im Zuckerrübenbau keine begünstigenden Wirkungen auf die Erreger des Wurzelbrandes. Das stellten das Institut für Zuckerrübenforschung in Göttingen und das Institut für Pflanzenpathologie und Pflanzenschutz der Universität Göttingen anhand von dreijährigen Versuchen fest. Aus: AID-Informationen, Bonn-Bad Godesberg, Jahrg. 25, Nr. 19, 1976.

\section{Aufforstung in Großbritannien}

Die Waldflädhe in Großbritannien beträgt heute etwa 1,6 Mill. ha, davon wurden 1 Mill. ha seit Ende des ersten Weltkrieges neu aufgeforstet. Den größten Teil dieser Arbeit leistete die staatliche Forstverwaltung, die Land ankauft und jährlich rd. 22000 ha neven Wald anlegt. Wie der Deutsche Rat für Landespflege in einem Reisebericht über Großbritannien in seiner Schriftenreihe berichtet, sind heute $8 \%$ des Landes bewaldet; angestrebt wird ein Waldanteil von $10 \%$. - In der Bundesrepublik sind $29 \%$ der Fläche bewaldet. Aus: AID-Informationen, Bonn-Bad Godesberg, Jahrg. 25, Nr. 18, 1976. 